\title{
Post Hoc Analysis of the Correlation Between Patient- Reported Outcomes and Clinical Response to Repository Corticotropin Injection for Persistently Active Rheumatoid Arthritis
}

\author{
Roy Fleischmann (D) · Kyle Hayes · Sung-Woo Ahn · George J. Wan • \\ Mary P. Panaccio · Daniel Karlsson · Daniel E. Furst
}

Received: October 15, 2021 / Accepted: December 1, 2021 / Published online: December 17, 2021

(C) The Author(s) 2021

\section{ABSTRACT}

Purpose: Approximately 6\% of patients with rheumatoid arthritis (RA) in the USA have refractory disease that is resistant to standardof-care therapies. A recent phase IV clinical trial affirmed the safety and efficacy of repository corticotropin injection (RCI; Acthar ${ }^{\circledR}$ Gel) for refractory RA. This post hoc analysis of the clinical trial data assessed whether changes in clinical measures correlated with patientreported outcome (PRO) improvements.

Methods: Data were assessed from the trial's open-label period when patients received RCI $(80 \mathrm{U})$ twice weekly for 12 weeks. Clinical assessments included hemoglobin A1c, C-reactive protein, erythrocyte sedimentation rate (ESR), total joint count (TJC), swollen joint count (SJC), Disease Activity Score with 28 joint

R. Fleischmann ( $₫)$

Metroplex Clinical Research Center, University of Texas Southwestern Medical Center, 8144 Walnut Hill Lane, Dallas, TX 75231, USA

e-mail: rfleischmann@arthdocs.com

K. Hayes - G. J. Wan - M. P. Panaccio - D. Karlsson Mallinckrodt Pharmaceuticals, Hampton, NJ, USA

S.-W. Ahn

KMK Consulting Inc, Morristown, NJ, USA

D. E. Furst

David Geffen School of Medicine, Division of Rheumatology, University of California Los Angeles, Los Angeles, CA, USA count and ESR (DAS28-ESR), and Clinical Disease Activity Index (CDAI). PROs included pain (Visual Analog Scale), fatigue (Functional Assessment of Chronic Illness Therapy-Fatigue [FACIT-F]), disability (Health Assessment Questionnaire-Disability Index [HAQ-DI]), and activity impairment (Work Productivity and Activity Impairment [WPAI] questionnaire). Patients grouped by minimal clinically important difference (MCID) improvement vs no improvement in PROs were compared with clinical measures at week 12. Correlations were determined by multivariable linear regression analysis and standardized coefficient estimates. Results: RCI responders, defined as patients with DAS28-ESR $<3.2$ at week 12 , reported significantly greater PRO improvements for pain, disability, fatigue, activity impairment, current work impairment, and overall work impairment than nonresponders. Patients with MCID improvements in all PROs showed significantly greater decreases in mean values for TJC, DAS28-ESR, and CDAI, whereas those with pain, fatigue, and disability improvements had significantly greater SJC and ESR reductions. Multivariable linear regression analysis determined that improvement from baseline in all PROs correlated with significant decreases in TJC, DAS28-ESR, and CDAI. ESR reduction significantly correlated with improvements in pain and disability, but not fatigue or WPAI.

Conclusions: These results confirm that clinical responses to RCI were directly correlated with patient perception of improvement. 
Keywords: Acthar Gel; Patient-reported outcomes; RCI; Repository corticotropin injection; Rheumatoid arthritis

\section{Key Summary Points}

Why carry out this study?

Approximately $6 \%$ of patients with rheumatoid arthritis (RA) in the USA have refractory RA that is inadequately responsive to standard-of-care therapies

Some studies suggest that physicianreported clinical metrics such as the Disease Activity Score with 28 joint count and ESR (DAS28-ESR) and Clinical Disease Activity Index (CDAI) may not correlate well with patient-reported outcomes (PROs)

The objective of this post hoc analysis from a recent clinical trial that demonstrated the safety and efficacy of repository corticotropin injection (RCI; Acthar ${ }^{\circledR}$ Gel) for the treatment of refractory RA was to determine whether the observed reductions in clinical values correlate with improvements in PROs

\section{What was learned from this study?}

PROs for pain, disability, fatigue, activity impairment, current work impairment, and overall work impairment showed greater improvements in RCI responders (DAS28-ESR < 3.2) than in nonresponders

Decreases in clinical measures such as DAS28-ESR, CDAI, and tender joint count significantly correlated with patient perception of improvement in pain, fatigue, disability, and activity impairment

\section{INTRODUCTION}

Rheumatoid arthritis (RA) is a chronic systemic autoimmune disease characterized by synovial inflammation that usually causes progressive damage to bone and cartilage in multiple joints with continued disease activity, which may lead to significant disability [1]. With the use of advanced medications over the past 2 decades, many patients experience an acceptable level of disease control, although it is estimated that approximately $6 \%$ of patients with RA in the USA (30,000-34,000 patients) have refractory RA resistant to all current therapies [1, 2]. Risk factors for refractory RA include female sex, smoking, obesity, earlier disease onset, longer time to first treatment, and higher baseline disease activity [3]. Because these patients have continued disease activity despite current therapy, they are in need of alternative treatments.

The American College of Rheumatology (ACR) and the European League Against Rheumatism (EULAR) both advocate a treat-totarget approach in treating patients with RA to a goal of remission or low disease activity (LDA) if remission is not possible $[4,5]$. Conventional synthetic disease-modifying antirheumatic drugs are the initial standard-of-care treatment for RA and should be initiated immediately following diagnosis [4, 5]. Short-term corticosteroid therapy is recommended by EULAR (but not the ACR) when beginning or changing disease-modifying antirheumatic drug dosing regimens to reduce inflammation [4-6]. The literature suggests that current therapies provide highly variable 1-year remission rates depending on the therapy and individual patient characteristics and that persistent disease activity may result in a significant decrease in patient function due to progressive bone erosion [5-7]. For the aforementioned reasons, there is an unmet need for additional therapies in patients with refractory RA [5].

Repository corticotropin injection (RCI; Acthar ${ }^{\circledR}$ Gel) is a complex mixture of naturally sourced adrenocorticotropic hormone analogs and other pituitary peptides with anti-inflammatory and immunomodulatory effects [8-10]. $\mathrm{RCI}$ is indicated for use as a short-term 
adjunctive therapy for acute episodes or exacerbations of RA, including juvenile RA [8]. Originally thought to function primarily by inducing cortisol production from the adrenal cortex through activation of melanocortin receptor 2 (MC2R), RCI has been shown to elicit direct immunomodulatory effects on various types of immune cells through other melanocortin receptors (MCRs) [10-12]. Preclinical studies have reported that RCI directly inhibits B cell proliferation [10, 11], antibody production [11], and inflammatory cytokine release from macrophages [12].

In vitro studies have shown that RCI activates all five MCRs with different binding and activation profiles than those observed with synthetic MCR agonists [13]. RCI is a partial agonist at MC5R and a full agonist at MC1R-MC4R [11]. RCI demonstrated much lower agonistic activity at MC2R compared with synthetic $\mathrm{ACTH}_{1-24}$, and studies in animals and healthy human subjects have confirmed that RCI produces substantially lower endogenous cortisol than synthetic $\mathrm{ACTH}_{1-24}[13,14]$. These data suggest that RCI may have multiple mechanisms of action, including steroidogenicindependent direct modulation of immune cells, that differ from those associated with other therapies.

The efficacy and general safety of RCI was reported from a multicenter, randomized, placebo-controlled, withdrawal clinical trial that evaluated RCI in the treatment of refractory RA [15]. With 12 weeks of open-label RCI therapy, $63 \%$ of patients experienced LDA, defined by Disease Activity Score with 28 joint count and erythrocyte sedimentation rate (DAS28-ESR) < 3.2 [15]. In a double-blind withdrawal period over 12 weeks, LDA was maintained in $61 \%$ of RCI-treated patients vs $42 \%$ receiving placebo [15]. When Clinical Disease Activity Index $(\mathrm{CDAI}) \leq 10$ was used as the LDA definition, LDA was maintained in $86 \%$ of RCI-treated and $66 \%$ of placebo-treated patients at week 24 [15].

Multiple patient-reported outcomes (PROs) were collected during this trial, and analysis revealed significant improvements with RCI treatment compared to baseline [15]. After RCI treatment, both fatigue, evaluated with the Functional Assessment of Chronic Illness
Therapy-Fatigue (FACIT-F), and disability, evaluated using the Health Assessment Questionnaire-Disability Index (HAQ-DI), were reduced by $39 \%$ and $49 \%$, respectively, and remained lower for 12 weeks after discontinuation of RCI [15]. In addition, significant improvements were reported in all four domains of the Work Productivity and Activity Impairment (WPAI) scale (work time missed, overall work impairment, impairment while working, and activity impairment) at week 12 and remained improved through week 24 [15].

The objective of this post hoc analysis is to determine the correlation between the clinical response to RCI treatment and improvements in PROs [15]. Correlating improvements in PROs with clinical outcomes provides further insights into patients' response to therapy and its impact on improvements in fatigue, pain, and disability [16].

\section{METHODS}

\section{Study Design}

The full clinical trial methodology from which this post hoc analysis is derived was previously published [15]. Patients with refractory RA received open-label RCI treatment $(80 \mathrm{U}$, twice weekly) for 12 weeks plus their background medications including glucocorticoids $(<10 \mathrm{mg}$ prednisone daily). Patients who experienced a DAS28-ESR $<3.2$ were classified as LDA responders. Responders were entered into a double-blind treatment period and randomized to continue receiving $\mathrm{RCI}$ or switched to placebo for an additional 12 weeks [15]. PROs were collected at baseline and every 4 weeks during the study.

\section{Post Hoc Analyses}

PRO scores were analyzed for improvement from baseline to week 12. PRO domains, their assessment questionnaires, and minimal clinically important difference (MCID) threshold values indicating the outcome of "improvement" are as follows: pain-Visual Analog Scale 
(0-100 mm scale), $\geq 10$-mm decrease $[17,18]$; fatigue-FACIT-F (0-52), $\geq 3$-point decrease [19]; disability-HAQ-DI (0-3), $\geq 0.22$ decrease [17]; and activity impairment-WPAI $(0 \%-100 \%), \geq 7 \%$ decrease $[15,20]$.

\section{Statistical Analyses}

Correlation of clinical manifestation to PRO scores was determined by multivariable linear regression analysis and standardized coefficient estimates. Outcomes were defined as changes in clinical covariates (independent variables) vs changes in PRO scores (dependent variables) from baseline to week 12. Clinical covariate measures included hemoglobin A1c (HbA1c), C-reactive protein (CRP), erythrocyte sedimentation rate (ESR), tender joint count (TJC), swollen joint count (SJC), DAS28-ESR, and CDAI. Multivariable linear regression models were analyzed for each PRO to control for patient age, sex, and race/ethnicity. Model assumptions were assessed using residual plots, generalized variance inflation factor, and $\mathrm{Q}-\mathrm{Q}$ plot; all assumptions were met. DAS28-ESR and CDAI were highly correlated with TJC and SJC, resulting in multicollinearity. Separate models were run for DAS28-ESR, CDAI, TJC, and SJC against all other covariates to generate individual estimates; no significant impact was detected on other covariate estimates. The adjusted $R^{2}\left(\mathrm{a} R^{2}\right)$ estimates were determined using the DAS28-ESR model. No regression analyses were performed using WPAI components for impairment while working, overall work impairment, or work time missed due to low sample size.

The number of PRO outcomes showing MCID "improvement" vs "no improvement" were compared with clinical correlates at week 12 and with the change in clinical correlates from baseline to week 12. Group comparisons were checked for normality using Shapiro-Wilk test. For normally distributed data, group comparisons between DAS28-ESR "responders" vs "nonresponders" and those reporting PRO improvement vs no improvement were compared using the independentsamples $t$ test. For nonnormally distributed groups, the Mann-Whitney $U$ test was used to confirm significance, unless the sample size was large enough ( $n>30$ per group) per the central limit theorem, then values from the independent-samples $t$ test were used. Categorical variables were compared using Pearson's chi-square or Fisher's exact test, as appropriate. All statistical analyses were two-tailed with a significance level of 0.05. Use of the term "significant" throughout this article refers to statistical significance. Statistical analyses were performed using SAS Enterprise Guide version 7.12 (SAS Institute) and R, version 3.2.1 (R Foundation for Statistical Computing).

\section{Ethics and Compliance}

This study was performed in accordance with the ethical principles outlined in the Declaration of Helsinki and its later amendments. The management of study data conformed to all applicable Health Insurance Portability and Accountability Act rules. All data were deidentified throughout the study to preserve patient anonymity and confidentiality. This post hoc study was conducted under the research exception provisions of the Privacy Rule, 45 CFR 164.514(e), and was exempt from institutional review board informed consent requirements. This study is based on a previously performed and published study and does not contain any new human participants.

\section{RESULTS}

RCI responders, defined as patients experiencing LDA (DAS28-ESR < 3.2) at week 12, reported significantly greater PRO improvements for pain, disability, fatigue, activity impairment, current work impairment, and overall work impairment than nonresponders (Fig. 1 and Table 1). Except for work missed, all PRO scores improved significantly more for responders than nonresponders from baseline to week 12 of RCI treatment in both mean PRO scores (Fig. 1) and change from baseline values (Table 1).

After 12 weeks of RCI treatment, patients exhibiting MCID improvements in PROs also displayed significantly greater differences in mean clinical assessment compared to those 


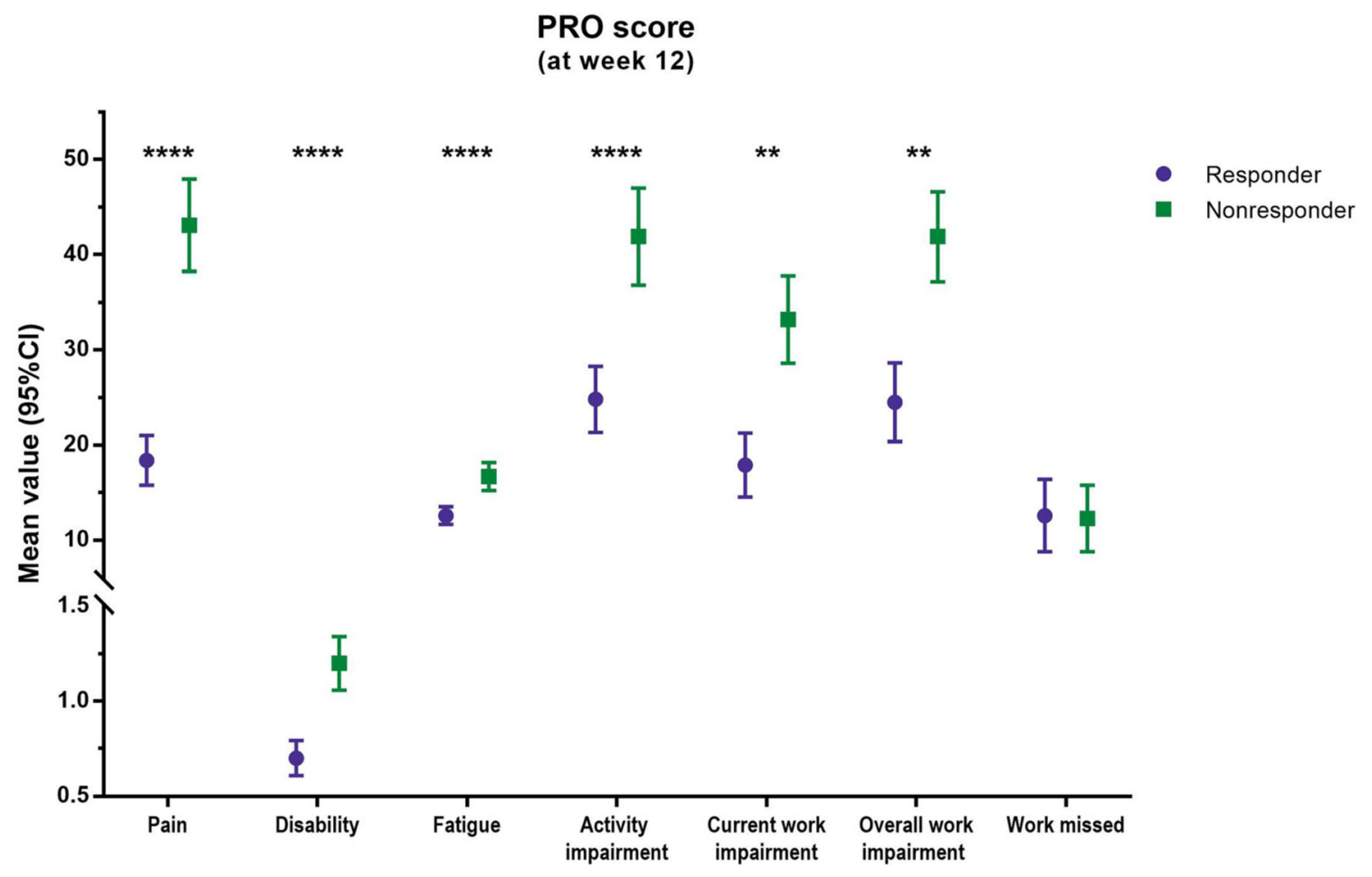

Fig. 1 Mean PRO scores at week 12 grouped by responders (DAS28-ESR < 3.2) or nonresponders to RCI treatment. Symbols represent mean change $\pm 95 \%$ confidence interval (CI). Statistical significance was determined using a two-sample $t$ test for normally distributed data and

showing no improvement (Table 2). TJC, DAS28-ESR, and CDAI values improved significantly for every improved PRO. Improvement in pain, fatigue, and disability significantly correlated with improvements in SJC and ESR. No significant differences were observed for HbA1c and CRP across any of the PROs. Table 2 also shows that more patients reported improvements in pain $(n=215)$, fatigue $(n=181)$, disability $(n=218)$, and activity impairment $(n=201)$ than those who experienced LDA $(n=163)$.

Mean changes from baseline to week 12 of RCI treatment demonstrated that patients exhibiting improvements greater than the MCID in each PRO had significantly larger reductions in DAS28-ESR vs those with no improvement (Fig. 2a). Patients exhibiting improvements greater than the MCID in pain, disability, and activity impairment had a
Mann-Whitney $U$ test for nonnormally distributed data. ${ }^{*} p<0.05, \quad{ }^{* *} p<0.01, \quad{ }^{* * *} p<0.001, \quad{ }^{* * * *} p<0.0001$. DAS28-ESR Disease Activity Score with 28 joint count and erythrocyte sedimentation rate, $P R O$ patient-reported outcomes, $R C I$ repository corticotropin injection

significantly larger reduction in CDAI vs those showing less than MCID improvement (Fig. 2b).

Bivariate comparison of mean changes from baseline to week 12 of RCI treatment in the individual component measures of DAS28-ESR (i.e., TJC, SJC, and ESR) with PRO improvement status showed that significant reductions in TJC correlated with improved pain and disability scores (Fig. 3a). Only improvement in pain correlated with a significantly lower SJC (Fig. 3b). ESR was reduced significantly for patients reporting improvement in pain, disability, and activity impairment (Fig. 3c).

Multivariable linear regression analysis determined that change from baseline values in all four PROs evaluated (pain, fatigue, disability, and activity impairment) correlated with significant decreases in TJC, DAS28-ESR, and CDAI (Table 3). Additionally, change in ESR significantly correlated with improvements in pain 
Table 1 PRO improvements from baseline to week 12 in RCI responders (DAS28-ESR $<3.2$ ) and nonresponders

\begin{tabular}{|c|c|c|c|}
\hline PRO & $\begin{array}{l}\text { Responder }^{\mathrm{a}} \\
\text { Mean change from baseline to } \\
\text { week 12, } n \\
(95 \% \mathrm{CI})\end{array}$ & $\begin{array}{l}\text { Nonresponder } \\
\text { Mean change from baseline to } \\
\text { week 12, } n \\
(95 \% \mathrm{CI})\end{array}$ & $p$ value $^{\mathrm{b}}$ \\
\hline Pain (VAS) & $\begin{array}{l}-47.3, n=163 \\
(-50.8 \text { to }-43.8)\end{array}$ & $\begin{array}{l}-20.3, n=95 \\
(-25.5 \text { to }-15.1)\end{array}$ & $<0.0001$ \\
\hline Disability (HAQ-DI) & $\begin{array}{l}-1.0, n=163 \\
(-1.1 \text { to }-0.9)\end{array}$ & $\begin{array}{l}-0.5, n=95 \\
(-0.6 \text { to }-0.4)\end{array}$ & $<0.0001$ \\
\hline Fatigue (FACIT-F) & $\begin{array}{l}-10.3, n=160 \\
(-11.6 \text { to }-9.0)\end{array}$ & $\begin{array}{l}-5.3, n=78 \\
(-6.7 \text { to }-3.9)\end{array}$ & $<0.0001$ \\
\hline Activity impairment (WPAI-1) & $\begin{array}{l}-38.8, n=160 \\
(-43.9 \text { to }-34.7)\end{array}$ & $\begin{array}{l}-20.6, n=78 \\
(-25.7 \text { to }-15.5)\end{array}$ & $<0.0001$ \\
\hline $\begin{array}{l}\text { Current work impairment } \\
\text { (WPAI-2) }\end{array}$ & $\begin{array}{l}-32.1, n=34 \\
(-35.8 \text { to }-28.4)\end{array}$ & $\begin{array}{l}-14.5, n=22 \\
(-19.2 \text { to }-9.8)\end{array}$ & 0.010 \\
\hline $\begin{array}{l}\text { Overall work impairment } \\
\text { (WPAI-3) }\end{array}$ & $\begin{array}{l}-32.6, n=34 \\
(-37.1 \text { to }-28.1)\end{array}$ & $\begin{array}{l}-14.4, n=22 \\
(-19.5 \text { to }-9.3)\end{array}$ & 0.018 \\
\hline Work missed (WPAI-4) & $\begin{array}{l}-14.1, n=36 \\
(-18.5 \text { to }-9.7)\end{array}$ & $\begin{array}{l}-5.3, n=22 \\
(-9.6 \text { to }-1.0)\end{array}$ & 0.195 \\
\hline
\end{tabular}

Values in bold are significant $(p<0.05)$

CI confidence interval, DAS28-ESR Disease Activity Score with 28 joint count and erythrocyte sedimentation rate, FACIT$F$ Functional Assessment of Chronic Illness Therapy-Fatigue, HAQ-DI Health Assessment Questionnaire-Disability Index, PRO patient-reported outcomes, $R C I$ repository corticotropin injection, VAS Visual Analog Scale, WPAI Work Productivity and Activity Impairment

${ }^{a}$ Responders are defined as patients who experienced low disease activity with DAS28-ESR score $<3.2$ at week 12 of RCI treatment

${ }^{\mathrm{b}}$ Statistical significance was determined by independent-samples $t$ test with unequal variance assumption

and disability but not fatigue or WPAI. Change in HbA1c, CRP, and SJC were not significantly correlated with PRO improvements in the regression analysis (Table 3 ).

\section{DISCUSSION}

A strong correlation between clinical parameters and PROs is important to understand whether reduction in disease activity translates to improvement in PROs. It has been shown that physician-reported clinical metrics such as the DAS28-ESR and CDAI may not correlate well with important measures from the patients' perspective, such as control of pain and fatigue or maintenance of physical function [21]. Evaluating PROs in the clinic to assess improvement in quality of life should provide physicians with a better real-world assessment of the overall effectiveness of therapy [22].

RCI has demonstrated clinical efficacy in patients with persistently active RA despite standard-of-care treatment, including glucocorticoids [15]. In this post hoc analysis, clinical efficacy of RCI significantly correlated with patient perceptions of improvement in pain, fatigue, disability, and several measures of activity impairment. Improvements in PROs, including fatigue, disability, and activity 


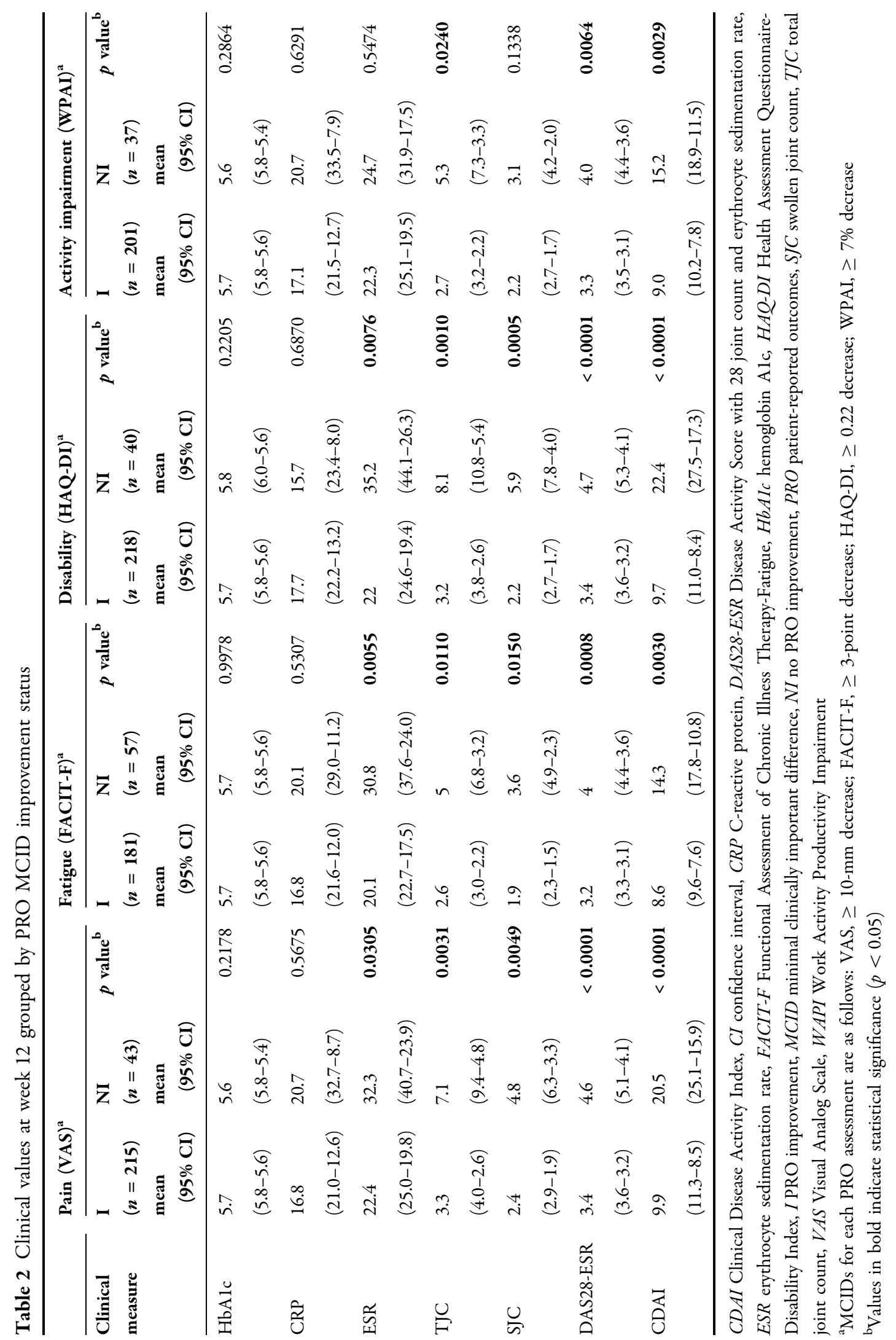



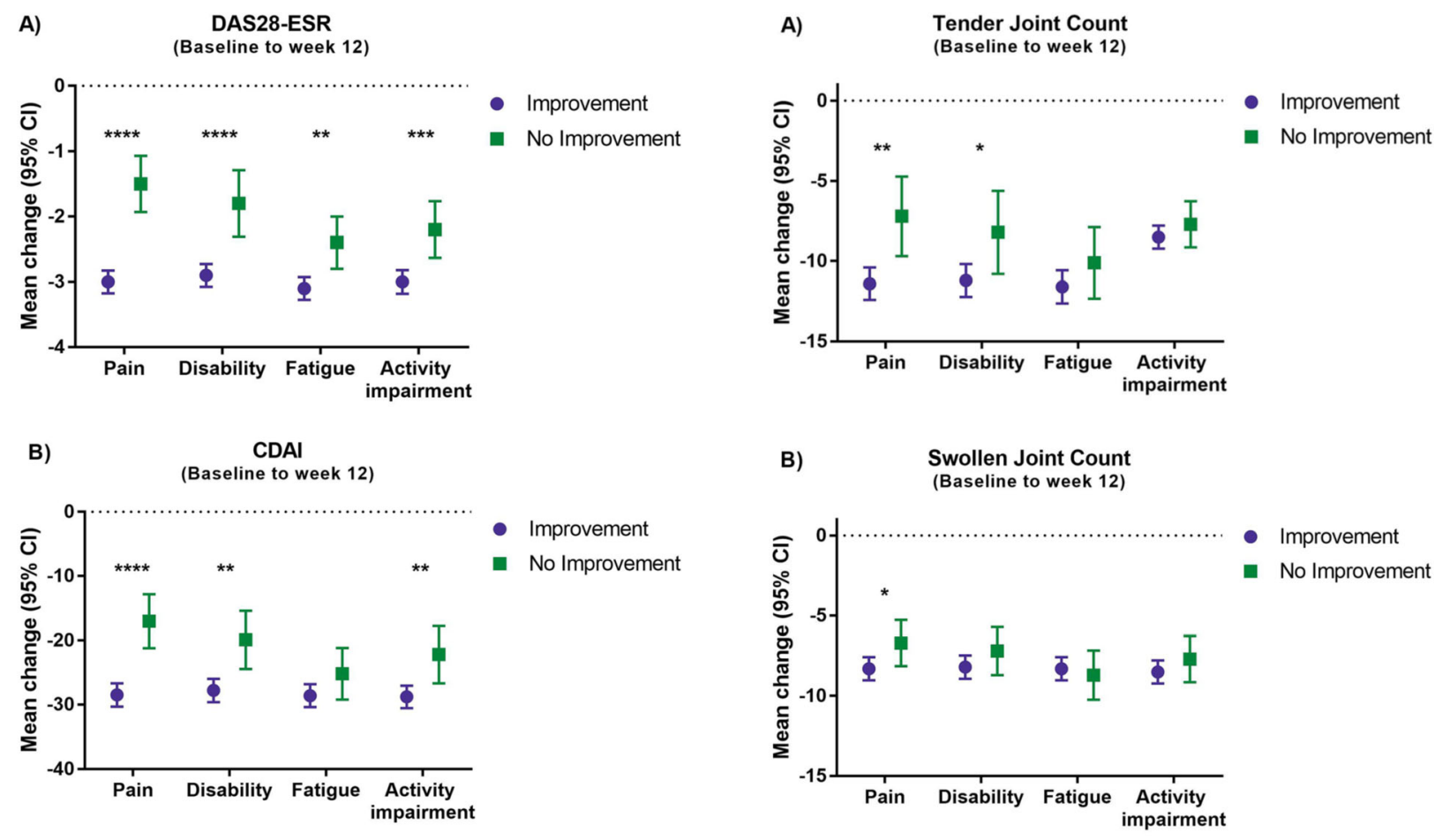

Fig. 2 Mean change in clinical disease severity measurements (DAS28-ESR or CDAI) from baseline to week 12 of RCI treatment grouped by MCID improvement status for each PRO. Symbols represent mean change \pm 95\% CI. Statistical significance was determined using two-sample $t$ test for normally distributed data and Mann-Whitney $U$ test for nonnormally distributed data. ${ }^{* *} p<0.01$, ${ }^{* * *} p<0.001,{ }^{* * * *} p<0.0001$. CDAI Clinical Disease Activity Index, $C I$ confidence interval, DAS28-ESR Disease Activity Score with 28 joint count and erythrocyte sedimentation rate, MCID minimal clinically important difference, $P R O$ patient-reported outcome, $R C I$ repository corticotropin injection

impairment, were maintained in the doubleblind withdrawal phase of the clinical trial after discontinuation of RCI, which suggests sustained quality-of-life improvement for patients with RA treated with RCI for at least 12 weeks postwithdrawal [15].

Limitations of this study, aside from this analysis being post hoc and not prespecified or properly powered, include that the majority of patients were of Hispanic/Latino ethnicity and located in Latin America, which may limit the generalizability of these results to other

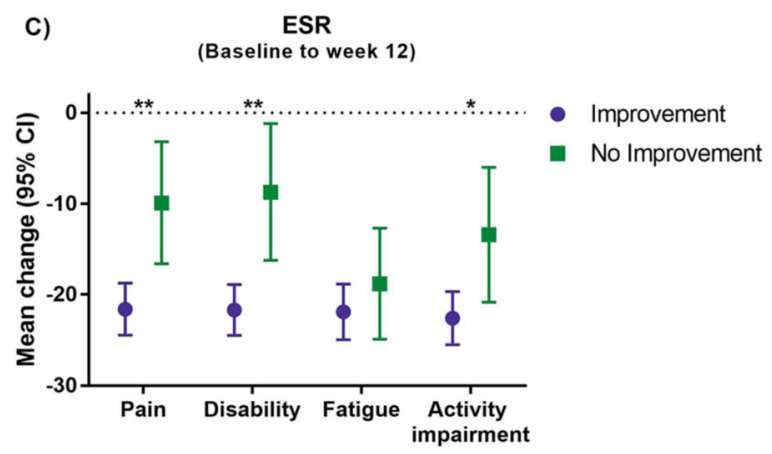

Fig. 3 Mean change from baseline to week 12 in components of the DAS28-ESR grouped according to PRO MCID improvement status. Symbols represent mean change $\pm 95 \%$ confidence interval (CI). Statistical significance was determined using two-sample $t$ test for normally distributed data and Mann-Whitney $U$ test for nonnormally distributed data. ${ }^{*} p<0.05, \quad{ }^{* *} p<0.01$, ${ }^{* * *} p<0.001,{ }^{* * *} p<0.0001$. DAS28-ESR Disease Activity Score with 28 joint count and erythrocyte sedimentation rate, ESR erythrocyte sedimentation rate, $M C I D$ minimal clinically important difference, PRO patientreported outcome

ethnicities and regions of the world [15]. In addition, PROs can be influenced by numerous 


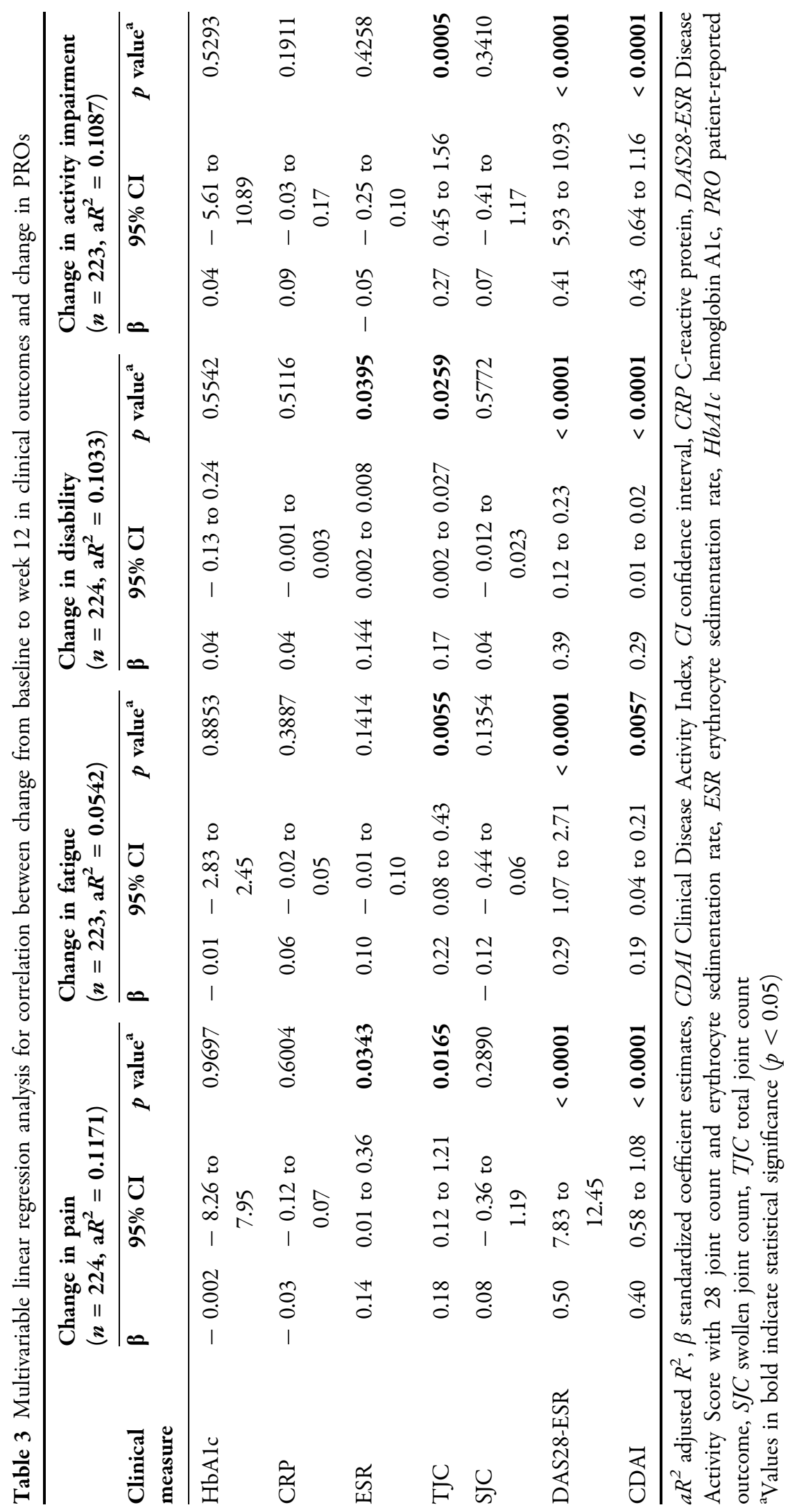


external factors including psychological distress and sleep disorders [23].

\section{CONCLUSIONS}

The results of this analysis suggest a direct correlation between the clinical responses to RCI and patient perception of symptom improvement in the treatment of refractory RA.

\section{ACKNOWLEDGEMENTS}

The authors would like to thank the patients who participated in this study.

Funding. Sponsorship for this study and the Rapid Service fee were funded by Mallinckrodt Pharmaceuticals (Hampton, NJ, USA).

Medical Writing and/or Editorial Assistance. Professional writing and editorial support were provided by Nestor G. Davila, PhD, of MedLogix Communications, LLC, Itasca, Illinois, USA, under the direction of the authors and was funded by Mallinckrodt Pharmaceuticals. The authors thank Elaine Böing for input on the early study design and protocol.

Authorship. All named authors meet the International Committee of Medical Journal Editors (ICMJE) criteria for authorship for this article, take responsibility for the integrity of the work as a whole, and have given their approval for this version to be published.

Author Contributions. All authors contributed to the conception or design of the study; acquisition, analysis, or interpretation of data; drafting or critically revising the manuscript for important intellectual content; and final approval of the manuscript.

Disclosures. Roy Fleischmann has received clinical trial grants from AbbVie, Amgen, AstraZeneca, BMS, Boehringer Ingelheim, Genentech, Gilead, GSK, Janssen, Eli Lilly, Pfizer, Roche, Sanofi-Aventis, Samumed, and UCB. He has received consultancy fees from AbbVie,
Amgen, BMS, Celltrion, Galvani, Gilead, GSK, Janssen, Eli Lilly, Novartis, Pfizer, and UCB. George J. Wan, Daniel Karlsson, and Kyle Hayes are employees of Mallinckrodt Pharmaceuticals. Sung-Woo Ahn and Mary P. Panaccio are paid consultants for Mallinckrodt Pharmaceuticals. Daniel E. Furst has received grants and consultancy fees from AbbVie, Actelion, Amgen, BMS, Corbus, NIH, Novartis, Pfizer, and Roche/Genentech. He has also received consultancy fees from Cytori and speaking fees from CMC Connect (McCann Health Company).

Compliance with Ethics Guidelines. This study was performed in accordance with the ethical principles outlined in the Declaration of Helsinki and its later amendments. The management of study data conformed to all applicable Health Insurance Portability and Accountability Act rules. All data were de-identified throughout the study to preserve patient anonymity and confidentiality. This post hoc study was conducted under the research exception provisions of the Privacy Rule, 45 CFR 164.514(e), and was exempt from institutional review board informed consent requirements. This study is based on a previously performed and published study and does not contain any new human participants.

Data Availability. The data sets generated and/or analyzed during the current study are available from Kyle.Hayes@mnk.com on reasonable request.

Open Access. This article is licensed under a Creative Commons Attribution-NonCommercial 4.0 International License, which permits any non-commercial use, sharing, adaptation, distribution and reproduction in any medium or format, as long as you give appropriate credit to the original author(s) and the source, provide a link to the Creative Commons licence, and indicate if changes were made. The images or other third party material in this article are included in the article's Creative Commons licence, unless indicated otherwise in a credit line to the material. If material is not included in the article's Creative Commons licence and your intended use is not permitted by statutory 
regulation or exceeds the permitted use, you will need to obtain permission directly from the copyright holder. To view a copy of this licence, visit http://creativecommons.org/licenses/by$\mathrm{nc} / 4.0 /$.

\section{REFERENCES}

1. Smolen JS, Aletaha D, Barton A, et al. Rheumatoid arthritis. Nat Rev Dis Primers. 2018;4:18001.

2. Hayes K, Panaccio MP, Goel N, Fahim M. Patient characteristics and indicators of treatment initiation with repository corticotropin injection in patients with rheumatoid arthritis: a claims database analysis. Rheumatol Ther. 2021;8:327-46.

3. Melville AR, Kearsley-Fleet L, Buch MH, Hyrich KL. Understanding refractory rheumatoid arthritis: implications for a therapeutic approach. Drugs. 2020;80:849-57.

4. Fraenkel L, Bathon JM, England BR, et al. 2021 American College of Rheumatology guideline for the treatment of rheumatoid arthritis. Arthritis Rheumatol. 2021;73:1108-23.

5. Smolen JS, Landewé RBM, Bijlsma JWJ, et al. EULAR recommendations for the management of rheumatoid arthritis with synthetic and biological disease-modifying antirheumatic drugs: 2019 update. Ann Rheum Dis. 2020;79:685-99.

6. Bijlsma JW, Boers M, Saag KG, Furst DE. Glucocorticoids in the treatment of early and late RA. Ann Rheum Dis. 2003;62:1033-7.

7. Donahue KE, Gartlehner G, Schulman ER, et al. Drug therapy for early rheumatoid arthritis: a systematic review update. Rockville, MD: Agency for Healthcare Research and Quality; 2018.

8. Acthar Gel. Package insert. Mallinckrodt Pharmaceuticals; 2021.

9. Ahmed TJ, Montero-Melendez T, Perretti M, Pitzalis C. Curbing inflammation through endogenous pathways: focus on melanocortin peptides. Int J Inflam. 2013;2013:985815.

10. Benko AL, McAloose CA, Becker PM, et al. Repository corticotropin injection exerts direct acute effects on human B cell gene expression distinct from the actions of glucocorticoids. Clin Exp Immunol. 2018;192:68-81.
11. Olsen NJ, Decker DA, Higgins P, et al. Direct effects of HP Acthar Gel on human B lymphocyte activation in vitro. Arthritis Res Ther. 2015;17:300.

12. Healy L, et al. Melanocortin receptor mediated antiinflammatory effect of repository corticotropin injection on human monocyte-derived macrophages [ECTRIMS abstract EP1481]. Mult Scler J. 2017;23(S3):777.

13. Huang YJ, Galen K, Zweifel B, Brooks LR, Wright AD. Distinct binding and signaling activity of Acthar Gel compared to other melanocortin receptor agonists. J Recept Signal Transduct Res. 2021;41(5):425-33.

14. Wang X, Pham L, Poola N, Brooks LR, Due B. Comparison of steroidogenic exposure following the administration of repository corticotropin injection with a synthetic $\mathrm{ACTH}_{1-24}$ depot and methylprednisolone in healthy subjects. Clin Pharmacol Drug Dev. 2021;10:777-88.

15. Fleischmann R, Furst DE, Connolly-Strong E, et al. Repository corticotropin injection for active rheumatoid arthritis despite aggressive treatment: a randomized controlled withdrawal trial. Rheumatol Ther. 2020;7:327-44.

16. Mercieca-Bebber R, King MT, Calvert MJ, Stockler MR, Friedlander M. The importance of patient-reported outcomes in clinical trials and strategies for future optimization. Patient Relat Outcome Meas. 2018;9:353-67.

17. Wolfe F, Michaud K. Assessment of pain in rheumatoid arthritis: minimal clinically significant difference, predictors, and the effect of anti-tumor necrosis factor therapy. J Rheumatol. 2007;34: 1674-83.

18. Wells GA, Tugwell P, Kraag GR, et al. Minimum important difference between patients with rheumatoid arthritis: the patient's perspective. J Rheumatol. 1993;20:557-60.

19. Cella D, Yount S, Sorensen M, et al. Validation of the Functional Assessment of Chronic Illness Therapy Fatigue Scale relative to other instrumentation in patients with rheumatoid arthritis. J Rheumatol. 2005;32:811-9.

20. Fleischmann R, Weinblatt ME, Schiff $M$, et al. Patient-reported outcomes from a two-year headto-head comparison of subcutaneous abatacept and adalimumab for rheumatoid arthritis. Arthritis Care Res (Hoboken). 2016;68:907-13.

21. van Tuyl LHD, Sadlonova M, Hewlett S, et al. The patient perspective on absence of disease activity in rheumatoid arthritis: a survey to identify key 
domains of patient-perceived remission. Ann Rheum Dis. 2017;76:855-61.

22. Singh H, Kumar H, Handa R, Talapatra P, Ray S, Gupta V. Use of clinical disease activity index score for assessment of disease activity in rheumatoid arthritis patients: an Indian experience. Arthritis. 2011;2011:146398.

23. Gossec L, Dougados M, Dixon W. Patient-reported outcomes as end points in clinical trials in rheumatoid arthritis. RMD Open. 2015;1: e000019. 